\title{
Transnational Environmental Crimes
}

\author{
Siniša Franjić \\ Independent Researcher, Osijek, Slavonia, Croatia.
}

How to cite this paper: Siniša Franjić. (2021) Transnational Environmental Crimes. Journal of Humanities, Arts and Social Science, 5(2), 249-254.

DOI: $10.26855 /$ jhass.2021.07.008

Received: August 7, 2021

Accepted: August 31, 2021

Published: September 7, 2021

${ }^{*}$ Corresponding author: Siniša Franjić, Independent Researcher, Osijek, Slavonia, Croatia.

Email: sinisa.franjic@gmail.com

\begin{abstract}
States may negotiate bilateral agreements on extradition and/or mutual legal assistance. Bilateral agreements can be very useful because they can be adapted to accurately reflect the legal systems and specific needs of the two countries. At the same time, it is easier to make changes and additions to them, in order to meet the requirements in the future. But negotiating bilateral agreements can be challenging when it comes to spending time and resources. The state sometimes needs to conclude a large number of such contracts to make sure that its potential interests are sufficiently met. Multilateral agreements have always been important in the context of international legal cooperation. The international community has begun to place increasing emphasis on the development of multilateral frameworks for cooperation on globally important issues. Examples of such emphasis include terrorism, drug trafficking, corruption, trade, the environment, and transnational crime. This paper discusses about certain environmental issues.
\end{abstract}

\section{Keywords}

Environment, Soil, Air, Water, Environmental Crime, Law

\section{Introduction}

Responding to environmental crime involves a wide range of collaborations across many different domains and sectors (Pink et al., 2016). This is especially the case when addressing transnational environmental crime and its associated global environmental harms.

Specific types of environmental crime as described in law include things such as illegal transport and dumping of toxic waste, the illegal transfer of hazardous materials such as ozone-depleting substances, the illegal traffic in radioactive or nuclear substances, the illegal trade in flora and fauna, and illegal fishing and logging. However, within green criminology there is a more expansive definition of environmental crime or harm that includes transgressions that are harmful to humans, environments, and non-human animals, regardless of legality per se; it also includes environment-related harms facilitated by the state, as well as corporations and other powerful actors, insofar as these institutions have the capacity to shape official definitions of environmental crime in ways that allow or condone environmentally harmful practices.

The devastating effects of environmental crime are not easy to determine or estimate (Jarrell, 2007). Although we gather and report a wide range of statistics of street and violent crime at the national, state, and local level, there are virtually no uniform or national statistics describing the status and impact of environmental crimes. There is a continuing debate over the consequences and extent of environmental pollution and serious questions over the impact of enforcement on the nation's competitiveness in global/domestic markets. The cost of environmental toxic abatement and clean up is often more than the government is willing to spend. Researchers suggest that environmental crime causes more illness, injury, and death than street crime.

Differing conceptions of harm give rise to different understandings and interpretations of the nature and dynamics of transnational environmental crime (White, 2011). One result of this is that contemporary discussions of transna- 
tional environmental crime engage with a wide range of issues. Among the many topics under scrutiny are phenomena such as:

- $\quad$ illegal transport and dumping of toxic waste;

- $\quad$ transportation of hazardous materials such as ozone-depleting substances;

- $\quad$ the illegal traffic in real or purported radioactive or nuclear substances;

- proliferation of 'e'-waste generated by the disposal of tens of thousands of computers and other equipment;

- $\quad$ the safe disposal of old ships and aeroplanes;

- local and transborder pollution, that is either systematic (via location of factories) or related to accidents (e.g. chemical plant spills);

- $\quad$ biopiracy in which Western companies are usurping ownership and control over plants developed using 'traditional' methods and often involving indigenous peoples in the third world;

- $\quad$ illegal trade in flora and fauna;

- $\quad$ illegal fishing and logging.

\section{Bioindicators}

As sensitive and ecologically relevant measures of environmental conditions, bioindicators can be used to assess the health of aquatic ecosystems which may be compromised by a variety of environmental stressors such as contaminants, sediments, nutrients, and varying temperature, salinity, and hydrologic regimes (Adams et al., 2000). The bioindicators approach is a proven bioassessment method that uses responses of key (sentinel) aquatic organisms both as integrators of stress effects and as sensitive response (early-warning) indicators of environmental health. This integrated approach involves measuring a suite of selected biological and ecological responses at several levels of biological organization from the biomolecular and biochemical to the community levels. When properly designed and applied in field situations, bioindicator studies can help identify causal mechanisms between environmental stressors and population and community-level effects, and serve as a basis for which the effectiveness of remedial actions on the health of aquatic organisms can be evaluated. Rapidly-responding sensitive biomarkers, such as biomolecular and biochemical responses, and slower- response ecologically relevant bioindicators, such as population and community responses, can be included in field bioassessment programs to provide measurement endpoints for use in environmental compliance, regulatory decision-making, and ecological risk assessments. This bioindicators approach should be particularly relevant in helping to identify and diagnose sources of stressors in environments impacted by multiple stressors. To demonstrate use of bioindicators in addressing water quality issues, spatial and temporal patters in various biological responses are related to spatial and temporal patterns of contaminants in two aquatic systems compromised by different stressors.

\section{Soil}

There is no universally satisfactory definition of the term "soil" (Andrasko, 1981). To the ecologist or agriculturist the soil is what plants grow in. The engineer deals with large bodies of material many feet in depth and is interested mainly in the mechanical behaviour of such material he uses for foundations. To the forensic scientist soil may be defined as the surface layer of the land surface of the earth.

Soil is an important type of physical evidence. It is found adhering to the suspect or transferred to or from the scene of crime. If the source of the soil can be identified with that found on the suspect it will support a hypothesis that the suspect had visited the scene.

The forensic examination of soils may be divided into two different types. The first type is very rare and requires an absolute identification of the geological source of its origin, but not necessarily of a particular place. The purpose of the second, more common type of investigation is to identify a particular place but not necessarily the geological source of the soil. Soil found on the shoes or clothing of a suspect is compared with the soil from a scene of crime. Likewise, soils from the tires or the undercarriage of motor vehicles are compared with those from specific locations.

Soil, as we know it today, has been formed over geological epochs. It is a dynamic part of the earth's geomorphic cycle of surface weathering, erosion, deposition, sinking, metamorphosis, mountain building etc. The exposure of the parent rock to the atmosphere, water, volcanic, glacial and other activities resulted in physical and chemical weathering and disintegration of many minerals. Since climatic, biotic, topographic and time factors influenced the chemical and mineralogical composition of soils, these soils represent today a very complex material. 


\section{Air Pollution}

Air pollution refers to the introduction of physico-chemical or biological materials into the atmosphere that may cause harm or discomfort to humans or other living organisms, or deterioration of the natural environment (Lakhani et al., 2010). The ambient and indoor air composition has a considerable impact on our health and quality of life. Air pollution and greenhouse gas emissions can have a considerable impact on the environment, including broader global environmental issues such as stratospheric ozone depletion and climate change. Air pollutants can be broadly classified as either primary or secondary. Usually, primary air pollutants are substances that are directly emitted from a natural or anthropogenic process, such as ash from a volcanic eruption, carbon monoxide (CO) gas from motor vehicle exhaust, or sulfur dioxide $\left(\mathrm{SO}_{2}\right)$ released from factories. However, primary pollutants do not, by themselves, produce all of the adverse effects of air pollution. Chemical reactions may occur among primary pollutants and constituents of the atmosphere. Subsequently, gaseous pollutants reacting with each other and with particles in the air produce a complex array of new chemical compounds. Air pollutants not directly emitted as such, but formed in the air, are called secondary air pollutants, which are responsible for several ill effects of air pollution such as smog, haze, eye irritation, and damage to vegetation and material.

\section{Fresh Water}

Fresh water has historically been a property of the rich and affluent classes that has enabled them to enhance their lifestyles and demonstrate their wealth. It has also been a means by which governments could advance their political capital amongst a populace seeking reassurance about the security of supply to meet a fundamental human need (Brisman et al., 2018.). The ongoing commodification of water continues to undermine and compromise 'water security'. In so doing, it erodes water quality and maintains an unequitable status quo of inaccessibility, notably for those most water scarce societies on the planet, taking us closer to a global emergency. Access to fresh water should be a 'right to life' and this is expressed in international conventions on human rights.

The world has enough freshwater to supply the global demand but nonuniform distribution of these reserves and other reasons have led to shortages in certain locations (Salam et al., 2018.). The United Nations (UN) estimates indicate that there are 1.2 billion people living in areas of physical water scarcity and another 1.6 billion people facing economic water shortage. In terms of water quality, there are 748 million people who lack access to an improved drinking water source. The shortage in both quantity and quality may likely spread and become more acute due to growing demands, unsustainable withdrawal rates, degradation of source water quality, and changing climate patterns. Understandably, the main impact of water shortage is on direct human consumption but other indirect impacts include those on energy supply, food production, and ecosystem.

Traditionally, the expansion of water resources mainly depended on the need of the expanding population for food, clothing, and modern energy. More recently, the rising standards of the middle-income group has led to sudden and sharp increases in the water consumption in both production and use. Economic growth coupled with higher living standards could be the reason that the growth of water demand is double that of population growth in the twentieth century.

\section{Phenomenon}

Environmental crime is a relatively new phenomenon (Spapens et al., 2014). This is not because pollution that causes harm to humans, fauna and ecosystems is new, to take one example, but because we did not start to view this behaviour as criminal until after the Second World War. Of course, acts that inflict environmental damage involving the immediate death of humans or that harm economic interests were punishable before environmental laws came into effect.

Today, a large and increasing number of rules and regulations encompass a broad range of behaviour in relation to the environment. The first main category of these laws relate to the pollution of the air, water and land. Examples include dumping waste or blending it with other goods, and importing and using illicit pesticides. The second main category concerns illegal acts that cause direct harm to flora and fauna, such as illegal deforestation and the poaching of and trading in protected wildlife. Apart from national environmental laws, recent decades have also seen the development of an elaborate international legal framework to fight transnational environmental crime. Examples include the Convention on International Trade in Endangered Species of Wild Fauna and Flora (CITES), the International Convention for the Prevention of Pollution from Ships (MARPOL) and the Basel Convention on the Control of Transboundary Movements of Hazardous Wastes and Their Disposal. In addition, entities such as the European 
Union have drafted regulations for the prevention of environmental harm and pollution, such as the European Waste Shipment Regulation (EWSR). For many green criminologists, however, the concept of environmental crime is still too narrow because it does not include equally harmful acts to the environment that have not (yet) been criminalized. Instead, they favour the concept of environmental harm, which includes behaviour contributing to global warming and loss of biodiversity, as well as legal deforestation and extensive fishing outside territorial waters.

Environmental crimes do not always produce an immediate consequence, and the harm may be diffused. The complexity of victimization - in terms of time, space, impact and who or what is victimized —is one of the reasons why governments and the enforcement community have trouble in establishing suitable and effective responses.

\section{Police Collaboration}

The dynamics of environmental crime are such that new types of skills, knowledge, and expertise need to be drawn upon as part of the law enforcement and regulatory response effort (Pink et al., 2016). The impetus to develop these is also driven by the fact that environmental crime at domestic and international levels is gaining increasing notice as a growing and significant crime type and a major threat to national security. One outcome of this heightened interest by national governments and their environmental regulatory and enforcement bodies is recognition that this will involve increased partnering and working with others, including nontraditional partners and stakeholders. Collaboration therefore is an indication of engagement, involvement, and support to assist on an issue, while at the same time it presents as a process and a means by which to measure outcomes.

Environmental crime poses particular challenges for environmental law enforcement, especially from the point of view of police interagency collaborations, the nature of investigative techniques and approaches, and the different types of knowledge required for dealing with specific kinds of environmental harm. Moreover, many of the operational matters pertaining to environmental crimes are inherently international in scope and substance. The complexity of environmental crime means that greater investment in enforcement policy, enforcement capacity, and performance management is sorely needed in most jurisdictions.

Environmental crimes may have local, national, regional, and global dimensions, and combinations thereof. They can be difficult to detect (as in the case of some forms of toxic pollution undetectable to human senses). They may demand intensive cross-jurisdictional negotiation, and even disagreement between nation-states, in regard to specific events or crime patterns. Some environmental crimes may be highly organised and involve criminal syndicates, such as illegal fishing and movement of illegal wastes. Others may include a wide range of criminal actors, ranging from the individual collector of endangered species to the systematic disposal of toxic waste via third parties. All of these elements and issues, in turn, affect collaborative responses.

\section{Law}

In order for any environmental regulatory approach to be effective, there must be a strong rule of law with a comprehensive enforcement programme that promotes and enforces compliance with the law, and that will encourage the regulated community to comply with the law (Jones et al., 2016). In addition, there must be adequate capacity within the country to implement the laws, both by the regulated community and by the government and civil society. 'Capacity' should be considered widely: the capacity for legislatures and parliaments to write enforceable laws; the capacity for environmental ministries to translate the law into effective regulations, permits, and other controls; the capacity for industry and other polluters to understand and comply with the law; the capacity for civil society and the public to oversee and hold accountable the government and the regulated community; and the capacity for police, inspectors, prosecutors, and judges1 to inspect for compliance, investigate violations, and enforce the law.

The complex interactions and procedures by which global environmental agreements are formulated, ratified, and implemented are rarely thought of as a system (Susskind, 1994). But these agreements are, in fact, governed by predictable sets of actors engaged in a relatively structured process of negotiation, constrained by formal and informal rules and customs. The "system", such as it is, exists by default in many cases, and its weaknesses may not be apparent. Before the treaty-making process can be strengthened, we must understand the way this system operates.

The actors in the environmental treaty-making system include governmental leaders, unofficial or nongovernmental interest groups (including environmental action organizations, business associations, and scientific associations), and multilateral entities - particularly agencies of the United Nations such as the United Nations Environment Programme, the World Bank, and the United Nations Development Program. These actors gather information, exchange ideas, formulate proposals, and meet in informal and formal sessions to negotiate, prepare legal documents, 
and vote whether or not to accept new responsibilities, including taxing themselves to cover the costs of monitoring their global environmental management efforts. They meet periodically to review how well they have done and determine whether or not to take further action.

Over the past four decades, considerable efforts have been made to improve management of human relationships with the environment (Baldwin et al., 2016). Countries have created environmental agencies, negotiated multilateral agreements, and undertaken new initiatives at the local, national, and international levels to protect human health, limit greenhouse gas emissions, conserve biodiversity and wildlife, and manage natural resources and sustainable development. These efforts have increasingly shown a collaborative nature and involved leaders in governments, parliaments, and the judiciary, in international organisations, businesses, and civil society, and in other sectors. Environmental officials have often been at the forefront of efforts to promote the rule of law and good governance through work to advance sustainable development objectives. These efforts and achievements have depended on significant collaboration at the individual, group, and agency/organisational levels.

\section{Interpol}

Dealing with global environmental harm will demand extraordinary efforts to relate to each other across distance, time, language, and cultural borders; to understand specific issues; to coordinate actions; to enforce international laws and conventions; and to gather and share information and intelligence (Higgins et al., 2016). Among the many issues pertaining to the proliferation of agencies dealing with environmental crime is that each may be driven by different aims and objectives, different methods of intervention, with different powers, and exhibiting different levels of expertise and collaboration with others. Another issue relates to the need to distinguish between organisational affiliation (which may be formal and policy oriented) and interagency collaboration (which refers to actual operational practices and linkages). In some cases, there is a clear need for capacity building in order for collaboration and, especially, for rapid response, to be successfully institutionalised as part of normal agency practice. There can also be agency differences in defining and interpreting just what the crime is and how it should be responded to-as in the case of breaches versus crime, customs offences versus fisheries offences, and so on.

As an international agency, the experience of INTERPOL can be called upon to deal with these kinds of issues and to help build further expertise and networks into the future. INTERPOL provides an active forum in which criminal investigators from around the globe meet to discuss issues such as determining the role of organised crime in specific types of criminal enterprises (e.g., people smuggling), and developing training and enforcement actions to combat particular sorts of criminal activity (e.g., illegal oil pollution into oceans, seas, and inland waterways). At a practical level, a productive strategy for harmonisation of enforcement efforts is to focus on consistency in delivering regulatory and enforcement tasks. In relation to this, INTERPOL provides invaluable forums for the exchange of information and knowledge transfer about 'best practice' and 'what works' in a variety of situations. Participation in common training programmes and attendance at conferences and workshops provides opportunities to enhance overall law enforcement capabilities as well as contributing to shared understandings and values in regard to specific types of criminal activity. Importantly, the use of regional case studies and reference to local experiences both reaffirms the importance of acknowledging specific jurisdictional differences as well as creating opportunities for the adoption of a more balanced view of what constitutes the most productive law enforcement approaches and strategies.

\section{Green Criminology}

Over the last 25 years, Green Criminology has developed in to a fertile area of study that now attracts scholars from around the world with a wide range of research interests and theoretical orientations (Brisman et al., 2017). It spans the micro to the macro-from work on individual-level environmental harms to business/corporate crimes to state transgressions - and includes research conducted from both mainstream and critical theoretical perspectives, as well as arising from interdisciplinary efforts.

Interests of Green Criminology are in the "theft of nature" and "poisoning of the land" that result from differential aspects of the exercise of power. Thus, Green Criminologists might view differently state-corporate initiatives from individual ones that, while still problematic, owe something to socio-economic structures. In other words, while Green Criminologists do not wish to absolve individual-level actions that are harmful to nature, Green Criminologists can recognize how these may be necessary for survival.

\section{Conclusion}

States cooperating through intergovernmental organizations have created a complex network of bilateral and 
multilateral agreements that provide the legal basis for international cooperation. When it comes to agreement-based cooperation, there are practical and strategic advantages. First of all, the treaty obliges the requested state to cooperate in accordance with international law. Second, agreements usually contain detailed provisions on the procedures and parameters of cooperation and therefore provide a higher level of security and clarity than most non-agreement mechanisms. Agreements can also provide forms of cooperation that would otherwise be unavailable.

\section{References}

Adams, S. M. and Greeley, M. S. (2000). "Ecotoxicological Indicators of Water Quality: Multi-Response Indicators to Assess the Health of Aquatic Ecosystems" in Belkin, S. (ed): "Environmental Challenges", Springer Science+Business Media, Dordrecht, The Netherlands, p. 103.

Andrasko, J. (1981). “Soil” in Maehly, A.; Strömberg, L. (eds.): “Chemical Criminalistics”, Springer-Verlag, Berlin, Germany, pp. 171-172.

Baldwin jr., G., Gerardu, J., Koparova, M. R., and Ruessink, H. (2016). "International Compliance and Enforcement Networks: The Critical Role of Collaboration in Environmental Protection” in Pink, G.; White, R. (eds): "Environmental Crime and Collaborative State Intervention”, Palgrave Macmillan; Basingstoke, UK, p. 21.

Brisman, A., Goyes, D. R., Mol, H., and South, N. (2017). "Introduction: The Theft of Nature and the Poisoning of the Land in Latin America" in Goyes, D. R.; Mol, H.; Brisman, A.; South, N. (eds): "Environmental Crime in Latin America—The Theft of Nature and the Poisoning of the Land”, Palgrave Macmillan, London, UK, p. 2.

Brisman, A., McClanahan, B., South, N., and Walters, R. (2018). "Water, Crime and Security in the Twenty-First Century—Too Dirty, Too Little, Too Much”, Palgrave Macmillan, Springer Nature, London, UK, p. 216.

Higgins, D. and White, R. (2016). "Collaboration at the Front Line: INTERPOL and NGOs in the Same NEST" in Pink, G.; White, R. (eds): “Environmental Crime and Collaborative State Intervention”, Palgrave Macmillan; Basingstoke, UK, pp. 113-114.

Jarrell, M. L. (2007). "Environmental Crime and the Media - News Coverage of Petroleum Refining Industry Violations", LFB Scholarly Publishing LLC, New York, USA, p. 6.

Jones, D. and Honorato, I. (2016). "Capacity Building and Collaboration: Enforcement Training to Build Capacity that Ensures Environmental Protection” in Pink, G.; White, R. (eds): “Environmental Crime and Collaborative State Intervention”, Palgrave Macmillan; Basingstoke, UK, p. 39.

Lakhani, A., Balasubramanian, R., and Gurjar, B. L. (2010). “Air Pollution Monitoring and Source Characterization” in Gurjar, B. L.; Molina, L. T.; Ojha, C. S. P. (eds): “Air Pollution-Health and Environmental Impacts”, CRC Press, Taylor \& Francis Group, Boca Raton, USA, p. 20.

Pink, G. and White, R. (2016). "Collaboration in Combating Environmental Crime-Making it Matter” in Pink, G.; White, R. (eds): “Environmental Crime and Collaborative State Intervention”, Palgrave Macmillan; Basingstoke, UK, pp. 3-13.

Salam, P. A., Pandey, V. P., Shrestha, S., and Anal, A. K. (2017). “The Need for the Nexus Approach” in Salam, P. A.; Shresthra, S.; Pandey. V. P.; Anal, A. K. (eds): "Water-Energy-Food Nexus - Principles and Practices”, American Geophysical Union, John Wiley \& Sons, Inc., Hoboken, USA, pp. 4-5.

Spapens, T. and White, R. (2014). "Introduction” in Spapens, T.; White, R.; Kluin, M. (eds): "Environmental Crime and Its Victims—Perspectives Within Green Criminology”, Ashgate Publishing Limited, Farnham, UK, p. 1.

Susskind, L. E. (1994). “Environmental Diplomacy—Negotiating More Effective Global Agreements”, Oxford University Press, Inc., Oxfors, UK, p. 11.

White, R. (2011). “Transnational Environmental Crime-Toward an Eco-global Criminology”, Routledge, Taylor \& Francis Group, Abingdon, USA, pp. 7-8. 